\title{
O consumo de marcas de luxo pensando em Baudrillard ${ }^{1}$
}

\author{
The consumption of luxury brands thinking Baudrillard \\ Lara Guerreiro Pires ${ }^{2}$ \\ (laraguerreirop@gmail.com) \\ Simone Antoniaci Tuzzo ${ }^{3}$ \\ (simonetuzzo@hotmail.com) \\ http://dx.doi.org/10.5216/cei.v16i2.29184
}

\section{Resumo}

Este trabalho busca trazer à discussão o consumo de luxo a partir de temas levantados pelo sociólogo francês Jean Baudrillard, autor de livros como "O sistema dos Objetos" e "A sociedade de Consumo". O recorde do campo de reflexão é feito em pontos, são eles: o objeto; a serialização da produção, o consumo; a comunicação neste contexto; e os excluídos do consumo. A atualidade das proposições de Baudrillard pode ser aferida na reflexão do mercado de luxo. Assim como no século passado como quando escreveu seu primeiro livro de expressão, os objetos continuam sendo portadores de significados muito além de suas funções técnicas.

Palavras-chave: Baudrillard. Objeto. Consumo. Comunicação. Exclusão.

\begin{abstract}
This paper is an attempt to discuss the luxury consumption from issues raised by the French sociologist Jean Baudrillard, author of books like "The System of Objects" and "The Consumer Society". To do so, specific points of consumer are adressed. They are: the object, the serialization of production, consumer, communication in this context, and those excluded from consumption. The actuality of Baudrillard's propositions is explicit on the analysis of luxury market. As in the last century, when he wrote his first book of expression, the objects remain carriers of meanings beyond their technical functions.
\end{abstract}

Keywords: Baudrillard. Object. Consumer. Communication. Exclusion

\section{Introdução}

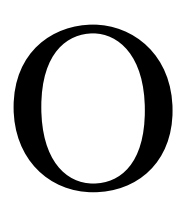

mercado de luxo cresceu consideravelmente no Brasil nos últimos anos com a abertura do País para importações, liberada em maior escala a partir do Governo Collor e com a estabilização da economia, a partir do Plano Real em 1994, no Governo Itamar Franco. A previsão de consultorias mercantis como a Bain \& Company apostam em um crescimento de até $25 \%$ entre 2013 e 2017 para o mercado de luxo. Dados como esse

\footnotetext{
${ }^{1}$ Este trabalho foi desenvolvido dentro do Projeto de Pesquisa Rupturas Metodológico para uma leitura crítica da Mídia entre os Programas de Pós-Graduação da UFG e UFRJ, que integra a ação transversal nº 06/2011 - Casadinho/Procad.

${ }^{2}$ Lara Guerreiro Pires é mestranda do Programa de Pós-Graduação em Comunicação, da Faculdade de Comunicação e Bibiloteconomia (Facomb), da Universidade Federal de Goiás (UFG).

${ }^{3}$ Simone Antoniaci Tuzzo é Doutora em Comunicação pela UFRJ, Mestre e Graduada em Comunicação pela UMESP, Coordenadora do Projeto de Pesquisa Rupturas Metodológicas para uma leitura crítica da Mídia entre os Programas de Pós-Graduação da UFG e UFRJ, que integra a ação transversal nº 06/2011 - Casadinho/Procad. Professora e Orientadora do Trabalho.
} 
tornam oportuna a reflexão sobre como o cidadão constrói a imagem do objeto de luxo e se predispõe a gastar dinheiro com produtos que não são de primeira necessidade. Este é um fato curioso uma vez que há crises econômicas surgindo em todo o mundo e manifestações públicas de insatisfação com políticas e práticas governamentais, tanto do Executivo quanto do legislativo, ganhando as ruas no Brasil e no mundo.

Para pensar o consumo de luxo, recorremos aos estudos de Jean Baudrillard sobre o objeto e o consumo. Não sendo a intenção exaurir a reflexão sobre o tema e, principalmente, do trabalho deste autor que possui mais de cinco dezenas de livros publicados, e outros tanto artigos, fez-se o recorte em pontos específicos do consumo. São eles: o objeto; a serialização da produção; o consumo; a comunicação neste contexto; e os excluídos.

\section{O objeto signo}

O objeto foi tema do autor francês em seu livro "O Sistema dos Objetos", publicado originalmente em 1968. No texto Baudrillard explica que o objeto moderno é resultado de suas relações com o mundo uma vez que ele deixou de ter uma função pré-determinada e não pode ser explicado unicamente pela sua utilização primeira.

\footnotetext{
Tentar explicar os objetos por suas relações em si mesmos não é o bastante, pois choca-se com a realidade psicológica e sociológica vivida dos objetos que constitui, para além de sua materialidade sensível, um corpo de coerções tais que a coerência do sistema tecnológico acha-se neles continuamente modificada e perturbada. É essa perturbação e como se desenvolve a racionalidade dos objetos em luta com as irracionalidades, e com tal contradição faz surgir um sistema de significações que se aplica em resolvê-la que nos interessa aqui, e não os modelos tecnológicos sobre cuja verdade fundamental, todavia, destaca-se continuamente da realidade vivida do objeto. (BAUDRILLARD, 2002, p.13-14).
}

O que podemos inferir é que o sociólogo, já em fins da década 1960, vislumbrava o objeto como símbolo da interação do indivíduo com a coletividade. Quando de sua análise, o mundo estava já 20 anos após a última grande guerra, se reconstruindo e fortalecendo sua economia por meio do consumo. A indústria, que não podia mais depender apenas da produção de armamento bélico, buscou cada vez mais alternativas para atender e criar mais anseios materiais para o indivíduo. O objeto, seja ele uma mesa ou um palácio, adquire várias novas auras que permitem que ele preencha diversos vazios. Para Baudrillard, essa nova situação é resultado da mudança social pela qual passou o mundo, como por exemplo, o espaço feminino na sociedade, a crescente migração do campo para cidade e, ainda, a disponibilidade da mão de obra que retornara da guerra. 
Tomando como exemplo o móvel, Baudrillard explica que a configuração do mobiliário é uma imagem fiel das estruturas familiares e sociais de uma época. Ele coloca que o interior burguês típico é de ordem patiarcal, no qual cada espaço e cada peça mobiliária tem espaço fixo e com funções definidas que pouco se alteram. Desta forma, ao mesmo tempo que mudam as relações do indivíduo na família e na sociedade, muda o estilo dos objetos mobiliários que "dobram-se, desdobram-se, são afastados, entram em cena no momento exigido" (BAUDRILLARD. 2002, p. 23).

Os objetos mudam em consonância com a mudança dos papéis desempenhados pelos indivíduos na família e na sociedade. Com a realidade social em que o espaço privado diminui surge a demanda que os objetos cumpram funções variadas. Eles são, então, libertos de suas funções primeiras, mas não tornados desnecessários, pelo contrário. Percebemos, então, que os objetos devem ter a capacidade de interagir com os demais objetos e com o indivíduo, sendo adaptável às necessidades que surgirem. "Os objetos não são mais investidos de uma "alma" assim como não mais os investem com sua presença simbólica: a relação faz-se objetiva, é combinação e jogo" (BAUDRILLARD, 2002, p. 13-14). Portanto, o valor tático do objeto torna-se maior que sua função primeira e seu valor estético.

A unicidade do indivíduo será percebida apenas pelo uso "único" que faz do objeto ou da combinação de objetos que possui. Assim, Baudrillard percebe que o sistema inteiro repousa sobre o conceito de funcionalidade, sendo ela a faculdade de integrar em um conjunto (1968). Como podemos pensar essa integração do conjunto de objetos?

O próprio Baudrillard aponta o caminho ao explicar que a coerência do sistema funcional dos objetos advém do fato de que estes não têm valor próprio, mas uma função universal de signo. Apresenta-se a oportunidade de pensar o que significa o consumo de luxo, de objetos de luxo, no sistema de objetos de Baudrillard uma vez que, como ele afirma, "o consumo, pelo fato de possuir um sentido, é uma atividade de manipulação de signos”. (BAUDRILLARD, 2002, p. 206).

Charles Pierce (1972) descreve o signo como aquilo que, sob certos aspectos e em alguma medida, substitui alguma outra coisa, representando-a para alguém. O pesquisador latinoamericano Juan Diaz Bordenave corrobora e complementa que o signo é todo objeto perceptível que de alguma maneira remete a outro objeto e que eles "têm função de signo em virtude de seu uso na sociedade" (BORDENAVE, 1982). Ele esclarece ainda que o conceito de signo envolve relações abstratas, decorrentes da capacidade de abstração do ser humano. Assim, um signo remete a um objeto ou 
também a um conceito, e seu significado não está apenas em si próprios, nem nos objetos, mas também nos conceitos ou imagens destes no imaginário das pessoas.

Bordenave (1982) aponta que o signo pode ter três tipos de significado. O primeiro é o "significado gramatical", o qual caracteriza o signo de acordo com sua relação com os outros elementos do discurso. O segundo é o "significado contextual", que explica o signo de acordo com o contexto no qual está inserido ou sendo utilizado, e em terceiro lugar o "significado referencial", que é o que liga o signo ao seu conceito referente. Estes significados são os explicados pelo dicionário e são avaliados por Bordenave como do tipo cognitivo já que se referem somente aos aspectos intelectuais da razão humana. Contudo, ele inclui neste hall o significado emotivo que está relacionado à reação emocional do individuo ao ter contato com o signo (1982, p. 70). Antes mesmo de Bordenave fazer estas reflexões acerca do signo, Charles Morris já havia classificado a semiótica em três aspectos: sintático, o qual delimita as relações dos signos entre si, de foma independente designam ou identificam; semântico, o signo em relação com os objetos designados; e o pragmático, sendo o signo em relação ao sujeito que os utiliza (RABAÇA e BARBOSA, 2001, p. 672).

Vemos essa divisão da semiótica no trabalho também de Peirce quando ele introduz a noção de interpretante:

\footnotetext{
Para ele, o signo deve ser compreendido como uma tríade que tem em sua base o símbolo ou representâmen, colocado em relação com um objeto que representa: no vértice do triângulo, o signo tem o interpretante (que alguns teóricos indentificam como o significado e a referência). Mas interpretante não deve ser confundido com intérprete (aquele que recebe o signo, decodificador, destinatário): "interpretante" é o intérprete ou usuário do signo, mas antes uma espécie de supersigno ou supercódigo individual ou coletivo que reelabora constantemente o seu repertório de signos em confronto com a experiência, conferindo ao signo, em última instância, o seu significado real, prático. O interpretante, assim, não é uma 'coisa' mas antes o processo relacional pelo qual os signos são absorvidos, utilizados e criados (PIGNATARIA, apud RABAÇA e BARBOSA, 2001, p. 673-674).
}

Recorrendo novamente a Bordenave, salienta-se que os signos têm significados diferentes de acordo com o contexto social em que se encontram. Para este trabalho é de primordial importância o entendimento da relevância da significação do signo, uma vez que para o estabelecimento de um produto como sendo de luxo é preciso que o consumidor interprete o produto como um signo de luxo, o qual possui significações muito além do seu puro uso técnico. Podemos depreender, então, que o consumir leva para casa não só um produto com funções específicas ou combinatórias, mas uma parte do sistema de objetos que possui e transmite um conceito, uma ideia, uma imagem, quissá uma reputação. 
Podemos entender que, para Bordenave, a construção do interpretante, deriva dos conceitos de denotação e conotação. $\mathrm{O}$ "significado denotativo aparece quando um signo indica diretamente um objeto referente ou suas qualidades", enquanto o "conotativo inclui as interpretações subjetivas ou pessoais que podem derivar-se do signo" (BORDENAVE, 1982, p. 72). Os dois últimos conceitos são especialmente importantes para nossa análise, pois é preciso entender que o que caracterizará o mercado de luxo será justamente a conotação dada a determinados objetos pelo consumidor.

A capacidade de abstração humana é o que torna o ser capaz de dar conotação aos signos, liberta o objeto de sua significação puramente referencial. "O significado conotativo permite tomar dados concretos da realidade atual ou histórica e extrapolá-los de tal maneira que toda uma nova realidade de significados é construída” (BAUDRILLARD, 1982, p. 75). Rabaça e Barbosa explicam a conotação como sendo

O sentido de uma palavra ou expressão ${ }^{4}$ constituído por elementos subjetivos, variáveis conforme o contexto. A significação neste caso sofre variações particulares de um indivíduo para outro, ou entre diferentes grupos da comunidade, ganhando valores secundários, basicamente simbólicos. Valor semântico suplementar da palavra. Opondo-se a denotação, significação de base comum que a todos os falantes, a conotação abrange o conjunto de significações associadas que a palavra desperta num indivíduo, grupo, classe ou comunidade. $\mathrm{O}$ valor conotativo incorpora significações produzidas pelo tratamento poético da palavra. (RABAÇA e BARBOSA, 2001, p. 180).

Podemos ilustrar com as figuras abaixo:

Tabela 1 - O carro como exemplo de significação do signo. A imagem, o sentido do objeto é construído pela práxis e com ele a imagem e auto-imagem de quem o possui

\section{Coluna A}

\section{Coluna B}

\footnotetext{
${ }^{4}$ Considero para este trabalho também o objeto-signo.
} 


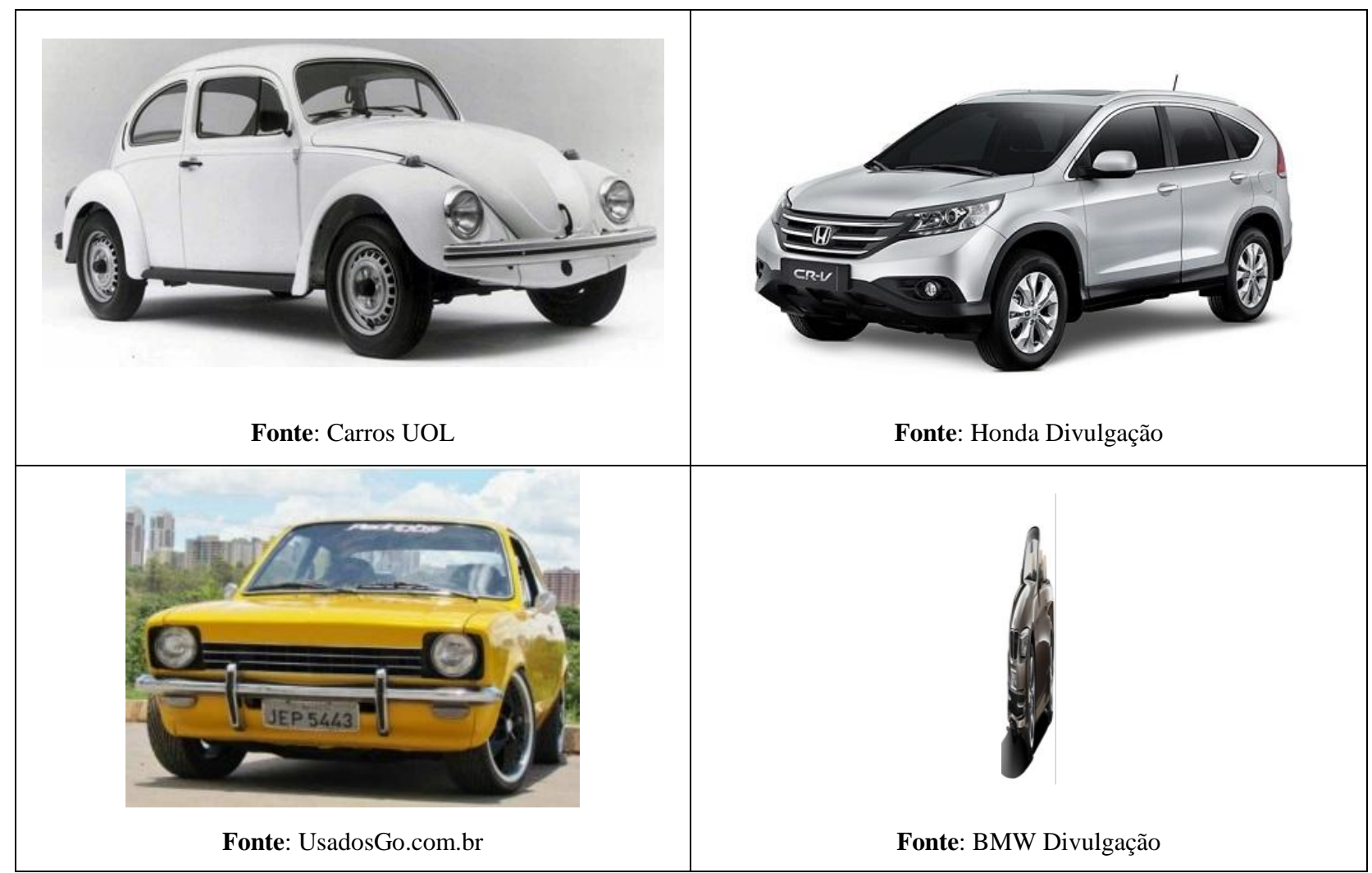

Os carros em ambas as colunas compartilham a denotação de "carro", porém não possuem a mesma conotação, podemos inferir que a interpretação do signo "carro" presente em todas as figuras serão muito diferentes a qualquer época. Enquanto, em 2013/2014, os objetos na Coluna A transmitem comumente uma ideia de velho, barato e feio, os que estão na Coluna B são associados a luxo, dinheiro, beleza e sucesso. Deve-se ressaltar novamente que a conotação que um indivíduo dá aos signos está intrinsicamente ligada ao seu imaginário que é construído, por sua vez, pelas suas interações sociais com outros indivíduos e com o meio ambiente.

\section{0 modelo e a série}

A modernização da indústria, da máquina a vapor à energia elétrica, possibilitou a produção em escala industrial de objetos antes criados peça a peça. Baudrillard analisa a produção industrial e afirma que "o estatuto do objeto moderno é dominado pela oposição modelo/série". Ele explica ainda que a série é baseada no modelo de estilo de minorias sociais abastadas, mas nunca existem concomitantemente ao modelo. Seguindo como exemplo a indústria automobilística, é notório que a tecnologia presente em carros de luxo não está disponível em sua plenitude nos modelos populares. Entretanto, segundo o autor, a série precisa colocar-se para o comum antes de o modelo virar 
passado para não perder a desejabilidade, mas nunca é o presente ou futuro do estado da arte. Produtos destinados apenas a elites com capacidade social e financeira tem acesso ao modelo.

No fundo a série não representa unicamente em relação ao modelo a perda da singularidade, do estilo, da nuança, da autenticidade, representa a perda da dimensão real do tempo. Pois unicamente os modelos mudam, as séries apenas se sucedem atrás de um modelo que sempre escapa mais além. (BAUDRILLARD, 2002, p. 160).

Refletindo nesta linha, podemos pensar que o modelo poderá ser o objeto de luxo máximo. Será o signo da exclusividade, do inacessível para a maioria, por isso, do luxo. Para a indústria a gradação desse luxo torna-se necessária para sua sobrevivência e assim chega-se ao objeto serializado, que é a simulação do modelo e age como agente de função ideológica, como diz Baudrillard (2010, p. 149), capaz de simular a liberdade. "O consumidor vive suas condutas distintivas como liberdade e como aspiração, como escolha, e não como condicionamento de diferenciação e de obediência a um código”. (BAUDRILLARD, 2010, p. 67).

Novamente tendo como exemplo o automóvel, as Ferraris, construídas manualmente, são o modelo do carro de sucesso e audácia. Não podendo ter acesso a esse modelo o consumidor comum pode escolher comprar um veículo com a cor símbolo, o vermelho. Para a maioria não é possível ter acesso ao modelo; entretanto, pelo objeto de série pode-se escolher a cópia que mais lhe convém de acordo com suas necessidades objetivas e subjetivas. Quanto mais cópias houver, maior a aura de luxo do modelo em si. Para ele:

Este sistema se apóia numa ideologia democrática: pretende ser a dimensão de um + processo social: possibilidade para todos de ter acesso pouco a pouco aos modelos, a ascendência sociológica contínua que traria, uma após outra, todas as camadas da sociedade para o maior luxo material e, de diferença em diferença "personalizada", para mais perto do modelo absoluto. (BAUDRILLARD, 2002, p. 162).

Baudrillard relata que a serialização permite ainda a personalização do modelo genérico que se constitui no que chamamos de moda. "É essencial que o modelo seja apenas a ideia do modelo". (BAUDRILLARD, 2002, p. 152). A personalização torna o objeto único, porém a serialização deixa-o mais frágil e efêmero em sua relação com o mercado. Ele perde o brilho muito rápido, seja pela substituição por um outro melhor tecnicamente ou simplesmente pela mudança da moda. São oferecidos objetos com pouca qualidade e ênfase no estilo, o qual deixará de agradar em pouco tempo sendo substituído por outro, de acordo com a lógica industrial. Para movimentar o consumo é preciso que o antigo seja trocado pelo novo e assim ele, o modelo, perde na série também a qualidade. Este aspecto é muito bem colocado e ampliado por Giacomini Filho. 
Os meios de produção tornam-se desconhecidos pelo consumidor, assim como componentes dos produtos e suas origens, agora transregionais. A escala industrial, pela estandardização e mecanização, reduz erros, mas se ocorrerem são multiplicados por milhões de unidades; a estandardização generaliza usos, gostos e costumes, desconectando usuários. A necessidade de alta produção obriga ao desgaste precoce e à obsolência dos produtos num prazo menor. Se o consumidor ganha no preço final, perde na durabilidade, se ganha na comodidade, perde na obsolência por moda ou desejabilidade (GIACOMINI FILHO, 1991, p. 33).

\section{0 consumo}

É oportuno questionar: qual motivo leva o consumidor a comprar a cópia do modelo? Porque o objeto em série faz tanto sucesso? Baudrillard aclara estas questões ao apontar Riesman, que é quem conclui que o produto mais procurado hoje não é mais alguma matéria prima ou máquina ou obra, mas uma personalidade. Esta é uma ideia central para Baudrillard tanto que aparece textualmente na obra "O sistema dos Objetos" (2002, p. 160), bem como em "A Sociedade do Consumo" (2010, p. 104). O indivíduo busca no consumo uma aspiração social que é um paradoxo, pois na busca por ser sujeito ele próprio tona-se mais um na lógica capitalista.

É preciso que fique claramente estabelecido desde o início que o consumo é um modo ativo de relação (não apenas com os objetos), mas com a coletividade e com o mundo, um modo de atividade sistemática e de resposta global no qual se funda todo nosso sistema cultural. (BAUDRILLARD, 2002, p. 206).

O consumo revela-se como linguagem e como diferenciação social, isto pois nunca se consome o objeto em si, mas seu significado, este dado ao objeto pela ambiência social. "Vamos nos afastando da época em que as identidades se definiam por essências a-históricas: atualmente, configuram-se no consumo, dependem daquilo que se possui, ou daquilo que se pode chegar a possuir" (CANCLINI, 1995, p. 14). O objeto não se apresenta sozinho mais em um contexto que leva o homem a não se satisfazer somente com o que precisa, pois não compra o que necessita para sobreviver, mas sim, a simbologia do objeto. Canclini assegura que:

quando selecionamos os bens e nos apropriamos deles, definimos o que consideramos publicamente valioso, bem como os modos com que nos integramos e nos distinguimos na sociedade, com que combinamos o pragmático e o aprazível (CANCLINI, 1995, p. 21).

O homem é um ser com necessidades e levado por sua natureza a satisfazê-las; o que faz por meio de escolhas. Baudrillard não nega que o consumidor tenha a liberdade de escolha e de saber o que quer, mas chama a atenção para necessidade de admitir a existência de uma <dinâmica social> 
das necessidades. Estas visam mais os valores atribuídos do que os objetos em si, e a satisfação diz mais respeito à adesão a estes valores. $\mathrm{O}$ indivíduo faz parte do grupo por meio do consumo e ao mesmo tempo consome para ser parte do grupo. É importante ressaltar que "as necessidades das classes médias e inferiores são sempre passíveis de atraso e de deslocamento no tempo e no plano cultural em relação às classes superiores” (BAUDRILLARD, 2010, p. 69).

Por conseguinte, a liberdade do consumidor não passa de uma criação utópica do próprio mercado incentivado pela variedade ofertada e destinada ao mesmo tempo a criar e a satisfazer desejos e escolhas individuais. No consumo, explica Baudrillard, o sistema alimenta-se a si prórpio criando cada vez mais produtos e estes criando a necessidade para eles próprios. Quanto mais possibilidades de consumo, aumento de renda, mais produtos são colocados à disposição, pois "não existem limites para as necessidades do homem enquanto ser social. Isto é, enquanto produto do sentido e enquanto relativo aos outros em valor.” (BAUDRILLARD, 2010, p. 72).

Nas palavras de Baudrillard (1968/2002), o consumidor é soberano "em plena selva de fealdade em cujo seio se lhe impôs a liberdade de escolha". Pois dar a opção de escolha é muito mais inofensivo do que dar ao indivíduo a liberdade de "ser" completamente autônomo. Completa ainda que as pessoas são categorizadas pelas categorias de objetos que possui (BAUDRILLARD, 2002, p. 199).

Gilles Lipovetsky, sociólogo francês da atualidade, colocou muito bem em entrevista ao site $i G$ que

As pessoas estão viciadas em novidades, como se não fosse possível viver sem isso. O consumo de luxo se tornou uma válvula de escape para aplacar desilusões e frustrações. Quer-se comprar felicidade, mas só se consegue uma satisfação passageira. Ao mesmo tempo, as marcas de luxo nunca foram tão populares e valorizadas, contrariando quem dizia que a difusão acabaria com o prestígio. Além disso, no Brasil, assim como na China, ainda havia uma demanda reprimida. As pessoas querem conhecer os produtos, as lojas, os vendedores. $(i G, 2012)$.

Baudrilard coloca ainda que a marca de um objeto não é nada mais do que a categorização dele próprio, o que nos leva a reflexão do autor sobre o código do "standing" (prestígio social). Ele determina que os objetos são categorias que de forma tirânica categorizam as pessoas. Pode-se perceber que esta é a categorização da importância social do objeto de acordo com a sua significação social, e concomitantemente do próprio consumidor. "Este código evidentemente se impõe mais ou menos segundo o quadro social e o nível econômico, mas a função coletiva da publicidade é a de converter a ele" (BAUDRILLARD, 2002, p. 202).

$\mathrm{Na}$ abundância desmedida das opções infindáveis o indivíduo consumidor fica como que obrigado a desfrutar. Baudrillard chama isso de obrigatoriedade do gozo. Para ele o ser humano faz 
sob pena de ser taxado de associal se não desfrutar da abundância e ser feliz com isso. A felicidade na sociedade de consumo tem de ser mesurável por objetos signos de conforto, esta ideia faz com que o indivíduo misture em seu inconsciente a noção de necessidade com a de bem-estar. "A felicidade constitui a referência absoluta na sociedade de consumo, revelando-se como o equivalente autêntico da salvação". (BAUDRILLARD, 2010, p. 49).

Isto leva a crer, portanto, que o consumo de produtos de luxo não é nada mais do que uma tentativa de estabelecer relação com o mundo em que o indivíduo é visto como especial, como pessoa de sucesso, de estilo. Zygmunt Bauman acrescenta ainda que as pessoas "aprendem que possuir e consumir determinados objetos e adotar certos estilos de vida é a condição necessária para felicidade, talvez até para a dignidade humana” (BAUMAN, 1999, p. 55-56). Atualizando a questão, Lipovetsky acredita que vivemos em uma eterna busca da felicidade privada e como o cidadão comum não tem tantos amores ou grandes emoções, o consumo é visto como um dos meios para alcançar essa felicidade. "O consumo funciona como um prazer fácil, que traz satisfação momentânea" (IstoÉ, 2012).

Há dois fatores muito importantes que estimulam o crescimento do mercado de luxo no Brasil, segundo a análise de Lipovetsky, a ascensão da classe média e o grande interesse por questões ligadas à aparência. Ele chama atenção para que o fato que esse crescimento também gera distorções e problemas na sociedade, pois o acesso à informação sobre o produto está disponíveis a todos, portanto tanto a classe alta quanto os mais pobres conhecem e desejam as marcas de luxo e para tê-las, alguns podem partir para a delinquência, o crime. "Antes os bandidos atacavam as pessoas porque precisavam de dinheiro para sobreviver, hoje porque querem ter roupas e carros de luxo para se exibir", sentencia Lipovetsky. Apresentam-se aqui dois aspectos da sociedade de consumo, quais sejam: a informação e a marginalização daqueles que não conseguem inserir-se neste contexto.

\section{Comunicação e consumo}

Nos textos de Baudrillard escolhidos para este estudo pode-se perceber que para o autor a comunicação exerce um papel fundamental na sociedade de consumo, caracterizada pela universalização do fait-divers na comunicação de massa. Sendo necessário relembrar que os faitdivers são as notícias que despertam interesse do leitor por suas características extraordinárias e ruptura com a normalidade do cotidiano. 
Outra nota importante neste momento é relembrar que Baudrillard não acredita em um conceito de massa determindado, pois antes de tudo não é um conceito. Explica que "só se comportam como massa aqueles que estão liberados de suas obrigações simbólicas, 'anulados' (presos nas infinitas 'redes') e destinados a serem apenas o inumerável terminal dos mesmos modelos" (BAUDRILLARD, 2005, p. 4). Esta elucidação contribui com nossa reflexão, podemos reconhecer o consumidor como receptor de modelos transmitidos pela indústria da comunicação pautada pelos diversos fatos espetaculares. Destarte podemos compreender melhor quando Baudrillard afirma que todo tipo de informação, seja ele de cunho político, econômico, cultural é transmitido sob a mesma fórmula e aparece dramatizada de forma espetacular que determina o esvaziamento do real. Assim, "as comunicações de massa não nos fornecem a realidade, mas a vertigem da realidade" (BAUDRILLARD, 2010, p. 25).

O autor se aproveita da teorização de Marshall McLuhan ao afirmar que os meios de comunicação de massa apresentam um tipo de mensagem em que reforçam a si mesmos. "A mensagem da TV não são as imagens que transmite, mas os novos modos de relação e de percepção que impõem, a mudança das estruturas tradicionais da família e do grupo" (BAUDRILLARD, 2010, p. 159). A mensagem é moldada sob o viés da espetacularização do desconhecimento do mundo e da valorização da informação como mercadoria, ou seja, do conteúdo como signo.

O problema aqui está em aos meios deixarem de centrar a mensagem no significado passam a centrar no significante. O exemplo da TV:

Ela não leva a ver nem à compreender os acontecimentos, mas os expõem a todos indiferentemente segundo idêntico código, que surge ao mesmo tempo como estrutura ideológica e como estrutura técnica - isto é, no caso da TV, o código ideológico da cultura de massa (sistema de valores morais, sociais e políticos) e o modo de corte e de articulação do meio de comunicação impõe determinado tipo de discursividade, que neutraliza o conteúdo multiplo e móvel das mensagens, pondo em seu lugar os próprios constrangimentos imperativos de sentido (BAUDRILLARD, 2010, p. 162).

Constata-se, portanto um processo de simulação da vida diária com base em imagens e modelos pré-concebidos e depara-se com a verdadeira realidade abolida em proveito do que Baudrillard denomina de neo-realidade do modelo materializado pelo próprio meio de comunicação. Contudo, as críticas do autor não são destinadas apenas aos meios, já que para ele "as massas resistem escandalosamente" ao imperativo da comunicação racional, que seria aquela voltada a melhor informar e/ou elevar o nível cultural. "O que se lhes dá são mensagem, elas [as massas] querem apenas signos, elas idolatram o jogo de signos e de esteriótipos, idolatra todos os 
conteúdos desde que eles se transformem numa sequência espetacular" (BAUDRILLARD, 2005, p. $6)$.

Deste contexto, da produção de mensagens a partir do próprio meio de comunicação e dos receptores querendo sempre mais esperacularização, originam-se e atualizam-se os signos de luxo e seus contrários. Em sua decorrência o modelo e a série de produtos e serviços infindáveis que se sucedem em uma luta inglória para alcancar o ideal de felicidade que o consumidor ainda nem imagina que exista. Esta ideia está expressa em Baudrillard com muita clareza não só quando ele discute a comunicação e a publicidade, mas também quando ao falar sobre o objeto explica que na atualidade (o texto é de 1968 e continua atual em muitos aspectos) "são os objetos que impõem seus ritmos descontínuos aos homens, sua maneira descontínua de se apresentarem, de se alterarem, de se substituírem uns aos outros sem envelhecer" (BAUDRILLARD, 2002, p. 169).

$\mathrm{Na}$ análise de Baudrillard a publicidade é o produto mais democrático que existe, pois é, em suas palavras, “ 'ofertado' e ofertado a todos” de modo que tem por função favorecer a assimilação espontânea dos valores sociais ambientais e a regressão individual no consenso social. Podemos entender, portanto, que a publicidade vende mais do que o produto - vende mesmo o que as massas querem, o espetáculo, o signo. Ela trabalha com a convunsão entre objeto e o desejo do objeto. Podemos inferir, então, que a publicidade de produtos de luxo visa muito mais vender a imagem de standing relacionada a ela do que simplesmente o produto, que não importa se é um perfume, uma roupa ou acessório para casa, ou carro, ou qualquer outro objeto de desejo criado.

A publicidade é antes de tudo destinada a dirigir o consumo. Faz com que o indivíduo acredite que a sociedade está se moldando a ele e suas necessidades/desejos, mas na realidade é o indivíduo que se dobra aos signos apresentados. Para acompanhar o mercado dos objetos-signo, a publicidade tira o valor de uso dos objetos para sujeitá-lo ao valor/moda e a renovação vertiginosa e manter a roda do consumo baseada na eterna insatisfação do consumidor.

Em seu trabalho de manipulação dos signos a publicidade é muito hábil, na visão de Baudrillard, pois retirando o valor de uso dos objetos ela consegue transformar todo "desejo", por mais íntimo que seja, em universal. Para ele "nenhum desejo, nem mesmo sensual, subsiste sem a mediação de um imaginário coletivo" (BAUDRILLARD, 2010, p. 188). Seu exemplo é que desejar uma mulher é subentender que todos os homens são capazes de desejá-la. No mercado de luxo, podemos ver como exemplo o desejo por um carro ultra moderno que é subentender que todos que tem o status e a condição social a que se almeja desejam esse mesmo carro, ou jóia, ou viagem. Seja o produto ou serviço que for a publicidade trabalha para criar no imaginário coletivo a necessidade 
não do uso, mas criação do desejo pelo standing agregado, que na verdade é ambicionado por todos. Então, o indivíduo busca destacar-se no consumo, o que é contraditório, pois de alguma forma ao se espelhar no modelo, faz o mesmo que outros tantos.

\section{Excluídos do consumo}

Chegamos ao último tópico, o problema social da sociedade de consumo que é a criação de uma massa de excluídos, aqueles que ficam a margem das possibilidades de consumo, seja do mínimo necessário, ou desejado. Para Baudrillard o círculo vicioso do crescimento gera gastos (ecológicos, econômicos e sociais) que antes de solucionar os problemas causados pelas crescentes diferenças sociais, faz com que elas cresçam ou permaneçam como estão mantendo o status quo social.

Baudrillard explica que a sociedade do consumo, no seu conjunto, resulta do compromisso entre princípios democráricos igualitários, que conseguem aguentar-se respaldando-se na ideia utópica da abundância e do bem estar, e o imperativo fundamental de uma ordem de privilégio e domínio. Mas para ele abundância é um mito, pois ela não pode ser vista como crescimento econômico e menospreza a ideia de que com a abundância algo "acabaria sobrando para os pobres". Pobres, para ele, são aqueles que, por qualquer razão, permanecem no exterior do sistema industrial, fora do crescimento". (BAUDRILLARD, 2010, p.52). Acreditar que algo sobraria para aqueles que não tem poder de compra é ilusão. O sistema se mantém em virtude da própria lógica de exclusão.

Seja qual for o volume absoluto das riquezas, haverá uma desigualdade correspondente. $\mathrm{O}$ crescimento não nos afasta nem nos aproxima da abundância. Encontra-se logicamente dela separado por toda a estrutura social (BAUDRILLARD, 2010, p. 52).

A abundância o foco se desvia do ter para o o que ter, quanto ter e quando ter. Assim informação, comunicação, consumo, cultura são transformados em produtos/signo, que quando não são acessíveis ao indivíduo pode deixá-lo em conflito com sua própria existêcia e com a sociedade. Lipovetsky (2012) coloca que a população pobre brasileira também deseja muito o luxo e que o Brasil é um dos países onde a paixão pelo luxo é mais evidente.

O lado ruim do desejo pelo luxo, para Lipovtsky (2012), não é apenas o risco do excesso, mas também o fato de que muitas pessoas sofrem porque acham que não consomem o suficiente e elas não podem pagar por todas as necessidades que acreditam ter. Como já exposto, o filósofo se preocupa com a entrada no mundo do crime destes que não conseguem se inserir na lógica do consumo. 
$\mathrm{Na}$ sociedade de consumidores, como a chama Bauman, atualização das necessidades do consumidor é tão perniciosa quanto indispensável para a manutenção do sistema. "Não pode dispensar seus mecanismos de elevação de sonhos e desejos dos consumidores a um estado de frenesi por mais prejudicial que essa tendência possa revelar-se”. (BAUMAN, 1998, p. 54).

Bauman concorda com Baudrillard e é claro ao dizer que quanto mais eficaz a sedução do mercado, mas segura e próspera é a sociedade de consumidores:

Todavia é ao mesmo tempo mais amplo e profundo o hiato entre os que desejam e os que podem satisfazer os seus desejos, ou entre os que foram seduzidos e passam a agir do modo como essa condição os leva a agir e os que foram seduzidos mas se mostram impossibilitados de agir do modo como se espera agirem os seduzidos (BAUMAN, 1998, p. $55)$.

Os impulsos sedutores [os quais podemos pensar com a informação e publicidade do objeto signo] são distribuídos, ofertados nas palavras de Baudrillard, de forma indiscriminada. O problema para Bauman é que existem muito mais daqueles que as ouvirão do que daqueles que podem responder com a ação desejada, como o planejado.

Aqueles que não têm a possibilidade de satisfazer o desejo são como qualquer outro regalado com o deslumbrante espetáculo dos que podem fazê-lo. Como muito bem exemplifica Edgar Morin, as celebridades são heróis do consumo que esbanjam seus estilos de vida espetaculares como incentivo ao consumo. Quando uma senhora reclama que o valor da Bolsa Família [que pode-se avaliar como gasto social em Baudrillard] não tem aumento há oito anos e que o valor não paga a calça jeans de marca cobiçada pela filha, ela está somente mostrando que o sistema da sociedade de consumo funciona. Que ela e sua filha estão à margem da sociedade do consumo, mas que ambicionam fazer parte e sentir a "felicidade" do consumo.

A compra a crédito dá mais uma oportunidade ao excluído de tentar adentrar o mundo do consumo, e ele se vê então de volta a uma situação feudal, como diz Baudrillard, em que cada fração do trabalho é devida antecipadamente. A diferença, explica, é que na compra o indivíduo se entrega espontaneamente. Assim o faz na ânsia de encontrar a felicidade do consumo em um objeto que se deteriora a cada vencimento da prestação, não pelo seu valor de uso, mas pela moda e é substituído por um novo desejo.

\section{Considerações finais}

O estudo de Jean Baudrillard sobre o consumo iniciado na década de 1960 mostra-se atual ainda em 2013 como podemos notar na aplicação de seus conceitos e exemplos em temas atuais 
como o crescimento do mercado de luxo. Baudrillard já vislumbrava a decadência do indivíduo frente ao desejo de consumo impossível de saciar.

$\mathrm{O}$ autor entende a necessidade do consumo visto à participação em uma sociedade que sobrevive pela troca. Entretanto chama a atenção para o fato de que os objetos metamorfoseados em signos tem um lugar mais importante na interação do indivíduo com a coletividade do que sua própria subjetividade.

Outro aspecto desta discussão é a importância da criação dos signos a partir de uma representação feita pelos veículos de comunicação a serviço da lógica industrial. Assim, o sujeito vê-se enclausurado em uma eterna luta para encontrar seu lugar tentando diferenciar-se do todo ao consumir o produto de série que é modelo para tantos outros indivíduos que estão na mesma situação.

Por fim relembra Baumam (1998) que a lógica do consumo cria e se mantém graças a uma linha de exclusão que serve como salvação para aqueles que conseguem sair de baixo dela e como uma ameaça constante para aqueles que tentam se equilibrar acima dela.

O consumo de produtos de luxo, que cresce no Brasil a taxas anuais maiores que a do PIB é um exemplo sincero na tentativa de aplicação dos conceitos e conclusões de Baudrillard. Assim o é, pois o que caracteriza um produto de luxo é realmente a reprensetação midiática destes produtos ou serviços que vão ilustrar um estilo de vida de classes abastadas que servem como modelo para a maioria da população que equilibra-se acima da linha de exlusão.

\section{Referências}

AGUIAR, Murilo. iG Economia: indústria do luxo cai na real no Brasil. São Paulo, 2013. Disponível em: <http://economia.ig.com.br/empresas/comercioservicos/2013-04-21/industria-doluxo-cai-na-real-no-brasil.html >. Acesso em: 16 jun. 2013.

BAUDRILLARD, Jean. O sistema dos objetos. São Paulo: Perspectiva, 2002.

BAUDRILLARD, Jean. A sociedade de consumo. Lisboa: Edições 70, 2010.

BAUDRILLARD, Jean. Tela total: mitos-ironias da era do virtual e da imagem. São Paulo, Sulina, 1997.

BAUDRILLARD, Jean. À sombra das maiorias silenciosas. [S.1]: Sabotagem, 2005.

BAUMAN, Zygmunt. O mal-estar da pós-modernidade. Rio de Janeiro: Jorge Zahar, 1998. 
CANCLINI, Néstor García. Consumidores e cidadãos: conflitos multiculturais da globalização. Rio de Janeiro: Editora da UFRJ, 1997.

GIACOMINI FILHO, Gino. Consumidor versus propaganda. São Paulo: Summus, 1991.

LIPOVETSKY, Gilles. O brasileiro tem paixão pelo luxo. Revista IstoÉ, n. 2231, 10 ago. 2012.

SODRÉ, M. Antropológica do espelho. Petrópolis, RJ: Vozes, 2002. 